\title{
NOTAS SOBRE ÉTICA E PSICOLOGIA DO TRÂNSITO: articulações ético-profissional no processo de avaliação psicológica
}

DOI: 10.22289/2446-922X.V7N1A22

\author{
Adrian Bezerra Assunção ${ }^{1}$ \\ Ana Carolina de Araújo Tomé \\ Vanessa Carneiro Bandeira de Carvalho
}

\section{RESUMO}

A ética é descrita como o conjunto de padrões comportamentais, concepções, valores e quaisquer outros aspectos que determinem as ações do indivíduo e/ou grupo social. No tocante à psicologia, tais padrões são regulamentados pelo Código de Ética Profissional do Psicólogo (CEPP), enquanto ferramenta que rege os princípios normativos e os comportamentos esperados aos profissionais da área. Logo, é estipulado também acerca das variadas áreas de atuação da psicologia, dentre elas a avaliação psicológica (AP) dentro do contexto de trânsito, sendo o papel do psicólogo indispensável ao processo de promoção da saúde, segurança e prevenção de acidentes, embora, na prática, atue tão somente com execução de psicotécnico. Assim, o presente estudo objetiva explanar articulações ético-profissional no processo de AP em contexto do trânsito. Ademais, utilizou-se como método a abordagem qualitativa, com objetivo descritivo, cujo recurso é a revisão narrativa de literatura, compreendendo o período de 2005 a 2020. No entanto, é possível inferir que tais fatores se encontram estritamente relacionados, tornando-se imprescindível sua articulação para execução de uma práxis psicológica efetiva e comprometida com o social.

Palavras-chave: Avaliação Psicológica; Ética Profissional em Psicologia; Psicologia do Trânsito.

\section{NOTES ON ETHICS AND PSYCHOLOGY OF TRANSIT: ethical- professional articulations in the psychological assessment process}

\section{ABSTRACT}

Ethics is described as the set of behavioral patterns, conceptions, values and any other aspects that determine the actions of the individual and / or social group. In refer to psychology, these standards are regulated by the Psychologist's Professional Code of Ethics (CEPP), as a tool that governs the normative principles and behaviors expected of professionals in the field. Therefore, it is also stipulated about the various areas of activity of psychology, among them psychological assessment (PA) within the context of traffic, the role of the psychologist being indispensable to the process of health promotion, safety and accident prevention, although, in practice, act only with psychotechnical execution. Thus, the present study aims to explain ethical-professional articulations in the PA process in the context of traffic. Furthermore, the qualitative approach was used as a method, with a descriptive objective, whose resource is the narrative review of literature, covering the period from

\footnotetext{
${ }^{1}$ Endereço eletrônico de contato: adrianassuncao.psi@hotmail.com

Recebido em 02/04/2021. Aprovado pelo conselho editorial para publicação em 18/05/2021.
} 
2005 to 2020. However, it is possible to infer that such factors are closely related, making their articulation essential for the execution of an effective and committed social praxis.

Keywords: Psychological Assessment; Professional Ethics in Psychology; Traffic Psychology.

\section{NOTAS DE ÉTICA Y PSICOLOGÍA DEL TRÁNSITO: articulaciones ético-profesionales en el proceso de evaluación psicológica}

\section{RESUMEN}

La ética se describe como el conjunto de patrones de comportamiento, concepciones, valores y cualesquiera otros aspectos que determinen las acciones del individuo y / o grupo social. Con respecto a la psicología, estos estándares están regulados por el Código de Ética Profesional del Psicólogo (CEPP), como una herramienta que rige los principios normativos y comportamientos esperados de los profesionales en la materia. Por lo tanto, también se estipula sobre las distintas áreas de actividad de la psicología, entre ellas la evaluación psicológica (AF) en el contexto de la circulación, siendo indispensable el papel del psicólogo en el proceso de promoción de la salud, seguridad y prevención de accidentes, aunque, en práctica, actuar sólo con ejecución psicotécnica. Así, el presente estudio tiene como objetivo explicar las articulaciones ético-profesionales en el proceso de AP en el contexto del tráfico. Además, se utilizó como método el enfoque cualitativo, con un objetivo descriptivo, cuyo recurso es la revisión narrativa de la literatura, que abarca el período de 2005 a 2020. Sin embargo, es posible inferir que dichos factores están estrechamente relacionados, por lo que su articulación es fundamental para la ejecución de una praxis social efectiva y comprometida.

Palabras-clave: Evaluación psicológica; Ética profesional en psicologia; Psicología del tráfico.

\section{INTRODUÇÃO}

A ética é uma nomenclatura cuja compreensão remete a aspectos de determinados padrões de comportamentos a nível cultural, de princípios, hábitos, valores, costumes, tradições e/ou quaisquer outras normas existentes na sociedade ou categoria profissional (Lins \& Borsa, 2017). Dito isto, a ética em psicologia é orientada pelo Código de Ética Profissional do Psicólogo (CEPP), o qual é definido como conjunto de princípios e condutas que regem a profissão, estabelecendo normativas comportamentais esperadas, buscando, desse modo, proporcionar reflexão, crítica e responsabilização profissional, a nível coletivo e/ou individual, frente às infrações que perpassam às práticas psicológicas (CFP, 2005).

A psicologia é uma profissão amplamente inserida no mercado de trabalho, em variados locais como: clínicas, hospitais, escolas, empresas, universidades, políticas públicas, trânsito, dentre outros. Assim, o artigo em questão se deterá a abordar aspectos envoltos na psicologia do trânsito, área cuja atuação segundo Lins e Borsa (2017), está direcionada ao processo instrutivo do 
comportamento humano, detendo-se a análise de condicionantes comportamentais, situacionais, perceptivos, cognitivos, do funcionamento psíquico e social dos indivíduos que se submetem ao processo de aquisição da Carteira Nacional de Habilitação $(\mathrm{CNH})$.

Necessariamente, o profissional de psicologia nesse contexto se utiliza da avaliação psicológica (AP) enquanto ferramenta primordial de laboração (Barroso, Scorsolini-comin, \& Nascimento, 2019). Nesse sentido, AP, é uma competência exclusiva do psicólogo, especialmente, quando se utiliza como recursos os testes psicológicos, com os quais tal profissional deve desempenhar sua prática obedecendo aos requisitos éticos propostos na resolução CFP $n^{\circ}$ 09/2018, considerando a integralidade, os determinantes sociais, culturais, bem como as circunstâncias socioeconômicas condizentes com a realidade individual (CFP, 2018).

Assim sendo, evidencia-se que a AP não deve ser diminuída apenas a uma prática de testagem psicológica ou a aplicação de exame psicotécnico, visto que este é um ramo da psicologia que está em constante progresso, onde se pesquisa constantemente sobre o comportamento do homem no contexto do trânsito; e sobre os instrumentos de mensuração que ajudam a aptidão dos motoristas (CFP, 2019a). Dito isto, a AP se configura como fenômeno obrigatório frente a aquisição CNH, desde o Código Nacional de Trânsito de 1966, instituindo que movimentos como Conselho Regional de Psicologia (CRP) e Conselho Federal de Psicologia (CFP) assegurassem amparo legal para atuação do psicólogo nessa conjuntura (Nakano, Sampaio, \& Silva, 2011).

Assim, objetiva-se explanar sobre articulações ético-profissionais no processo de AP no contexto de trânsito. Oportunamente, o interesse pelo tema germinou-se a partir dos estudos na formação em avaliação psicológica e a partir da própria observação da invisibilidade de profissionais de psicologia que atuam no interior do Ceará. Logo, a pesquisa é relevante para o contexto sociopolítico, primordialmente, para profissionais de psicologia, por instigar a reflexão e ampliar conhecimentos relativos ao tema, bem como, ao cenário acadêmico, haja vista a construção de novos arcabouços teóricos.

Desse modo, o artigo encontra-se organizado em quatro eixos temáticos, sendo eles: (I) Ética profissional em psicologia; (II) Psicologia do trânsito, versando sobre o papel do psicólogo nesse contexto; (III) Avaliação psicológica no trânsito; e (IV) Articulações ético-profissional no processo de avaliação psicológica em cenário de trânsito. Os pontos elencados serão abordados no decorrer do trabalho, objetivando proporcionar ao leitor a ampliação de conhecimentos sobre o tema.

\section{METODOLOGIA}

A pesquisa em questão trata-se de um estudo de ordem qualitativa, cujo objetivo principal concerne na interpretação das significações que os indivíduos atribuem a determinado fenômeno, 
as quais são perpassadas por aspectos históricos, sociais, culturais e pessoais. Assim, realizar-seá a descrição e categorização do assunto versado, direcionando o pesquisador a confirmação ou refutação das hipóteses traçadas inicialmente, haja vista a exposição do tema e verificação do conteúdo, para que posteriormente ocorra a elaboração de inferências; considerando sua classificação com objetivo descritivo.

Do mesmo modo, se utilizou da revisão narrativa de literatura enquanto recurso técnico, a qual corrobora para elucidação, afirmação, negação, análise, questionamentos e desenvolvimento temático, utilizando-se como base, pesquisas já publicadas em meios digitais e/ou livros que contribuem para a compreensão do assunto, clarificando-o ao pesquisador e leitor. Nesse sentido, a coleta de informações sobre o tema ocorreu por meio de livros sobre AP, periódicos eletrônicos como, Scientific Eletronic Library Online (SCIELO) e Periódicos Eletrônicos em Psicologia (PEPSIC), bem como, no Código de Ética Profissional do Psicólogo (CEPP), cujo período referência entre os 15 anos - 2005 a 2020. Ainda, tem-se como base os descritores: avaliação, psicologia e trânsito.

Para tanto, posterior a escolha da literatura basilar, realizou-se a organização do material em eixos temáticos, dentre eles: avaliação psicológica, ética profissional e psicologia do trânsito, a partir da leitura flutuante, com elegibilidade dos recursos necessários - escolha de artigos e capítulos de livros - para a construção da revisão de literatura desse artigo. Dentre os critérios de inclusão, tem-se artigos dos últimos dez (10) anos, legislações e livros versando sobre o tema e a possível articulação entre os eixos temáticos e literaturas em língua portuguesa.

\section{DESENVOLVIMENTO}

\subsection{A PSICOLOGIA DO TRÂNSITO}

A aproximação entre psicologia e trânsito não é algo recente, sendo utilizada no processo aquisição de $\mathrm{CNH}$ antes da profissão ser regulamentada no Brasil (CFP, 2019a). Desde 1966 já se falava sobre a obrigatoriedade da inserção de psicólogos e da avaliação psicológica nesse cenário (Nakano, Sampaio, \& Silva, 2011), embora, somente, em 1998, através da resolução de n 80, de 19 de novembro de 1998, o Conselho Nacional de Trânsito (CONATRAN) tenha dado visibilidade à AP, enfatizando a importância de o psicólogo inserir-se no trânsito afim de auxiliar na compreensão psíquica dos sujeitos (Silva, Mendes, \& Silva, 2018). Contudo, somente a partir da resolução de no 12, no ano de 2000, do Conselho Federal de Psicologia (CFP), instituiu-se o manual de AP de candidatos a CNH, inserindo a AP no panorama de afluência (CFP, 2009).

Neste prisma, destaca-se que ao lidarmos com situações que envolvam o trânsito, a presença de profissionais de psicologia visa sensibilizar os indivíduos do seu papel enquanto 
condutores (CFP, 2009). Assim, a psicologia contribui de maneira a auxiliar na lida com o descumprimento de leis do trânsito, redução de conflitos, negligência e acidentes em espaços com fluxo de indivíduos e veículos (Silva, Mendes, \& Silva, 2018), atuando de maneira preventiva, no intuito de reduzir o envolvimento de motoristas em situações consideradas de risco, instigando a modificação comportamental e mudanças significativas em ambiente de trânsito (Nakano, Sampaio, \& Silva, 2011).

Dito isto, o papel do psicólogo do trânsito é de promotor da saúde, mediante ações de cunho preventivo, com desenvolvimento de intervenções psicológicas, o qual identificará comportamentos danosos e orientará formas de manuseio benéfico de veículos e atos passivos quando em uso de transportes, sejam públicos e/ou privados (CFP, 2009; Borges \& Rodriguez, 2020). Destaca-se que AP busca também proporcionar segurança para todos que compõem o trânsito, sejam eles motoristas e/ou pedestres (CFP, 2019a).

\subsection{AVALIAÇÃO PSICOLÓGICA NO TRÂNSITO}

A AP, é uma área de atuação ampla e dotada de pormenores, a qual proporciona ao profissional de psicologia o entendimento do funcionamento psíquico, cognitivo, social, psicomotor, em um dado momento de sua história, considerando o aspecto dinâmico e não cristalizado do psiquismo humano. Assim, é possível, mediante o uso de testagem psicológica, observações clínicas e comportamentais, entrevistas e análise de documentos, que sejam elaboradas inferências, as quais contribuirão para o alcance do objetivo inicial do processo de AP (Lins \& Borsa, 2017; Barroso, Scorsolini-comin, \& Nascimento, 2019).

Dito isto, se pensarmos no cenário do trânsito e observarmos as exigências do DETRAN, como, por exemplo exame de proficiência psicológica, bom desempenho em provas teóricas e práticas e, igualmente, treino de habilidades para motoristas e motociclistas; tem-se como ferramentas importantes para a realização da AP, o uso de testes psicométricos e/ou projetivos, os quais objetivam averiguar a parcela da personalidade do sujeito avaliado, frente ao construto que se propõem a analisar; questionários e/ou entrevistas, visando coletar informações necessárias ao processo de aquisição de $\mathrm{CNH}$; diagnosticando os indivíduos como aptos ou inaptos através dos recursos utilizados na AP (Bezerra et al., 2018; Silva, Mendes, \& Silva, 2018).

Sem embargos, a decisão do profissional de psicologia em espaços de afluência, contribuirá para que o trânsito seja um local seguro e com motoristas conscientes de seu papel, considerando ainda que mediante a testagem psicológica, é possível que ocorra a predição de comportamentos a serem manifestados por determinados sujeitos (Bezerra et al., 2018).

Oportunamente, a testagem psicológica auxiliará na análise das funções mentais como: inteligência, atenção, memória, impulsividade, capacidades cognitivas, características de 
personalidade, orientação global e capacidade geral para administrar veículos, a qual corrobora para que sejam analisadas funções psíquicas, indicadores - ou não indicadores - psicopatológicos e atitudes humanas em circunstâncias específicas, requerendo maestria na administração de conflitos e habilidades interpessoais (Silva, Mendes, \& Silva, 2018).

Desse modo, a entrevista e questionários deverão ser contidos de questões específicas ao espaço de tráfego e, igualmente, o processo de escolha dos testes deverão se valer de construtos e materiais elaborados para tal conjuntura como, a Bateria de Funções Mental para Motoristas (e suas variações), além de materiais não específicos mas que podem ser adaptados para tal objetivo, como, a Bateria Geral de Funções Mentais I e II, Teste Pictórico de Memória, Teste de Memória Visual e de Rostos, Teste Não Verbal de Inteligência, Teste Palográfico, Escala Fatorial de Ajustamento Emocional/Neuroticismo, Teste de Atenção Concentrada, Pirâmides Coloridas de Pfister, Escala de Avaliação de Tendência a Agressividade, Teste Conciso do Raciocínio, Psicodiagnóstico Miocinético, Teste Não Verbal de Inteligência Geral (BETA 3), dentre outros que o profissional julgar necessário ao processo avaliativo (Lins \& Borsa, 2017).

Os testes, bem como, seus respectivos construtos são apresentados na tabela 1:

Tabela 1 - Lista de instrumentos e construtos analisados

\begin{tabular}{|c|c|}
\hline Instrumento & Construto \\
\hline $\begin{array}{l}\text { Bateria de Funções Mental para Motoristas } \\
\text { (e suas variações) }\end{array}$ & Atenção \\
\hline Bateria Geral de Funções Mentais I e II & Atenção \\
\hline Teste Pictórico de Memória, & Memória \\
\hline Teste de Memória Visual e de Rostos & Memória \\
\hline Teste Não Verbal de Inteligência & Inteligência \\
\hline Teste Palográfico & Personalidade \\
\hline $\begin{array}{l}\text { Escala Fatorial de Ajustamento } \\
\text { Emocional/Neuroticismo }\end{array}$ & Personalidade \\
\hline Teste de Atenção Concentrada & Atenção \\
\hline Pirâmides Coloridas de Pfister & Personalidade \\
\hline $\begin{array}{c}\text { Escala de Avaliação de Tendência a } \\
\text { Agressividade }\end{array}$ & Personalidade \\
\hline Teste Conciso do Raciocínio & Inteligência \\
\hline Psicodiagnóstico Miocinético & Personalidade \\
\hline $\begin{array}{l}\text { Teste Não Verbal de Inteligência Geral } \\
\text { (BETA 3) }\end{array}$ & Inteligência \\
\hline
\end{tabular}


Fonte: elaborada pelas autoras (2021), baseada em Lins e Borsa (2017).

\subsection{ARTICULAÇÕES ÉTICO-PROFISSIONAL NO PROCESSO DE AVALIAÇÃO PSICOLÓGICA EM CENÁRIO DE TRÂNSITO}

A ética, conforme definição do dicionário Aurélio, é uma palavra de tradução grega, ethos, que significa a origem dos costumes, modo de agir, orientação, bem como, análise dos comportamentos humanos em determinada cultura ou sujeito, considerando sempre os valores morais estipulados. Logo, é caracterizada como um aglomerado de normas, condutas e moralidade presentes em determinada pessoa e/ou grupo social no qual pertence (Ferreira, 2009). Ainda, é uma nomenclatura que remete a aspectos de determinados padrões comportamentais a nível cultural, de princípios, hábitos, valores, costumes, tradições e/ou quaisquer outras normas existentes na sociedade ou categoria profissional (Lins \& Borsa, 2017).

Dito isto, a ética em psicologia é orientada pelo Código de Ética Profissional do Psicólogo (CEPP), datado do ano de 2005, o qual é definido como conjunto de princípios e condutas que regem a profissão, estabelecendo normativas comportamentais esperadas, buscando, desse modo, proporcionar reflexão, crítica e responsabilização profissional, a nível coletivo e/ou individual, frente às infrações éticas que perpassam às práticas psicológicas (CFP, 2005).

O CEPP ainda expressa a concepção de homem e sociedade determinada pela psicologia, a qual coloca-se em postura livre de preconceitos (quanto ao sexo, gênero, classe social, religião, ideologias, dentre outros), estigmas, desigualdades, relações de poder, ideologias políticas e/ou quaisquer outros fatores que sejam geradores de divisão de opiniões, sendo imparcial, respeitando toda e qualquer forma de diferença entre os povos, prezando por direitos humanos, sociais e igualitários quando no desempenho de sua laboração na condição de psicólogo (CFP, 2005).

Consoante, a AP é um processo breve, à medida que é amplo, por analisar variados construtos e funções psíquicas, não se restringindo ao uso de testes, podendo se valer de quaisquer recursos que o uso por psicólogos ou psicólogas seja regulamentando pelo CFP (Lins \& Borsa, 2017), dentre eles, entrevistas, anamneses, protocolos, registros observacionais e documentos técnicos, os quais deverão apresentar evidências empíricas, científicas e qualidade técnica para seu uso no processo de testagem psicológica (CFP 2018). Ainda, em caso de utilização de testes, só poderão ser aplicados instrumentos cujo prazo de validação esteja favorável e conste no Sistema de Avaliação de Testes Psicológicos (SATEPSI) (CFP, 2018; CFP, 2019b).

Assim, Lins e Borsa (2017) dizem que é imprescindível atentar-se aos objetivos da AP e buscar respondê-los, optando pelo menor prejuízo ao avaliando. Logo, se relacionarmos com o CEPP, poder-se-ia destacar as alíneas $\mathrm{g}, \mathrm{h}$ e j, ainda do artigo $2^{\circ}$, as quais abordam, 
respectivamente, sobre emissão de documentos; inferência na avaliação dos resultados, sua precisão, fidedignidade e validade (CFP, 2005), os quais são apresentados na tabela 2:

Tabela 2 - Alíneas dispostas no artigo $2^{\circ}$ do CEPP

\section{Artigo 2 do CEPP}

Alínea $g$

Alínea $h$

Interferir na validade, fidedignidade, bem como, adulterar seus resultados

e tecer falsas declarações

Estabelecer com a pessoa atendida ou demais pessoas do seu contexto,

Alínea j vínculos que interfiram negativamente na prestação do serviço

psicológico

Fonte: elaborada pelas autoras (2021), conforme o CEPP (2005).

Portanto, atuar contra alguma dessas assertivas é arriscar-se a agir desconforte o preconizado nas normativas, podendo interferir negativamente no processo de construção do conhecimento, bem como, tornar o resultado do serviço prejudicial ao indivíduo avaliado, seu bemestar psíquico, assim como a comunidade de maneira geral. Outrossim, caso haja realização de qualquer conduta desconforme em contexto de trânsito, primordialmente, quando se fala da aquisição de $\mathrm{CNH}$ ou quaisquer outras demandas que o psicólogo atue, ao agir de maneira oposta ao preconizado no CEPP, o profissional arriscar-se-á na tomada de decisões prejudiciais ao indivíduo (Lins \& Borsa, 2017).

Frente ao exposto, todo processo de AP, resulta na elaboração de documentos psicológicos, sejam eles a nível comprobatório - como a declaração - ou até mesmo atestados, laudos, relatórios psicológicos e relatórios multiprofissionais, cujo seguimento dos princípios técnicos, de linguagem, organização estrutural e norteadores éticos, necessitam o alinhamento ao documento e processo no qual se realiza, prezando pela imparcialidade profissional e busca de menor prejuízo (CFP, 2019b).

Para tanto, pautar-se no CEPP, principalmente, no artigo $9^{\circ}$, o qual versa sobre a obrigatoriedade da manutenção do sigilo profissional, é uma tarefa a ser exercida pelo profissional de psicologia em todas as áreas, incluindo a AP (CFP, 2005) e âmbito de trânsito (Lins \& Borsa, 2017), apresentado na tabela 3:

Rev. Psicol Saúde e Debate. Jun., 2021:7(1): 315-326. 
Tabela 3 - Artigo 9ำ do CEPP

\section{Artigo 9 do CEPP}

É dever do psicólogo a manutenção e guarda das informações sob sigilo profissional, protegendo a intimidade das pessoas ou organizações que tenham acesso no decorrer da prestação de serviços

Fonte: elaborada pelas autoras (2021), conforme o CEPP (2005).

Neste prisma, é possível, quando necessário, que o psicólogo possa atuar de maneira interventiva no tocante às demandas que adentram o campo da AP (CFP, 2019b), até mesmo se for em locais de tráfego, uma vez que ao identificar circunstâncias que apontem sofrimento psíquico, poderá desenvolver um plano de trabalho, visando reformular as adversidades que perpassam tais sofrimentos. Não obstante, é de suma importância que o profissional tenha consciência quanto aos preceitos estabelecidos no CEPP, quando se propor a realizar serviços, assumindo suas responsabilidades, competências e respaldo teórico-técnico na efetividade do serviço, visando tornar o trânsito um local saudável, seguro, de sujeitos responsáveis e comprometidos com o espaço de afluência, evitando conflitos e prejuízos à quem nele se insere (Lins \& Borsa, 2017).

Por fim, é obrigatoriedade de o psicólogo fornecer serviços de qualidade, seja a nível individual ou coletivo, garantindo a execução dos direitos humanos e respeito a cidadania (CFP, 2005; CFP, 2019b), sendo salutar que busque especializar-se na área da AP, caso desejem sua laboração, prezando por uma boa prática e qualificação técnica (Lins \& Borsa, 2017), através da especialização em psicologia do trânsito (Bezerra et al., 2018). Portanto, atuar frente ao psicotécnico é, sobretudo, estar disponível a exercer esse serviço com ética, compromisso, cuidado, promoção de bem-estar individual e coletivo, reduzindo danos psicológicos, seguindo e não ferindo os artigos dispostos no CEPP e resoluções vigentes, além de buscar respaldo teórico-técnico necessário para desempenhar uma atuação efetiva e livre de quaisquer impasses.

\section{CONSIDERAÇÕES FINAIS}

Frente ao exposto, tem-se a observação e o argumento acerca da imprescindibilidade da atuação do psicólogo no contexto do trânsito, uma vez que contribuirá positivamente para o manejo de circunstâncias de tráfego, enquanto promotor da saúde, visando ainda, a redução de acidentes através da conscientização dos indivíduos. Contudo, seu papel na prática, se opõe ao preconizado 
em legislações, sendo tal conduta restritiva e desconforme, atuando tão somente mediante a realização de psicotécnico, ou seja, com testagem psicológica. Logo, não poder-se-ia atribuir a parcela de responsabilidade ao profissional de psicologia, dado que cumpre normativas e exigências do Estado, sendo o trabalho moldado conforme os recursos que dispõe em sua prática.

No tocante a ética e sua articulação com AP, é notório o quanto ambas se aproximam e devem ser aplicadas nos mais variados contextos, nesse caso, na conjuntura de trânsito, como abordada no decorrer do estudo. Desse modo, ética, AP e trânsito, possuem estrita relação, depreendendo que o CEPP não se aplica somente a clínica, mas em todas as áreas de inserção do psicólogo, sendo algo universal à categoria. Entretanto, tais fenômenos por vezes se distanciam diante da complexidade e do quantitativo de impasses que a prática requer, considerando nosso sistema público, e político, enquanto dotado de falhas e aspectos que dificultam uma laboração ética e comprometida com o comunitário.

Por conseguinte, destaca-se as limitações e lacunas no que diz respeito a dificuldade na coleta de material teórico sobre a relação entre AP, ética e psicologia do trânsito, dado a escassez de trabalhos publicados referentes ao tema, trazendo a reflexão quanto a necessidade de se produzirem novas pesquisas para ampliação de conhecimento profissional e esclarecimento de dúvidas sobre o assunto versado, não somente por aqueles intitulados pesquisadores, mas pela categoria profissional e sistema de conselho de maneira geral. No âmbito da psicologia do trânsito ainda há muito o que percorrer, faz-se de grande relevância que os profissionais atuantes na área exponham o seu dia a dia profissional de modo a dar conhecimento à categoria e propor a implementação de melhorias no espaço do tráfego. É urgente a atualização de conhecimentos e medidas neste âmbito da sociedade. 


\section{REFERÊNCIAS}

Barroso, S. M.; scorsolini-comin F.; Nascimento, E. do. (2019). Avaliação Psicológica: contextos deatuação, teoria e modos de fazer. Nova Hamburgo: Sinopsys. ISBN: 978-8595011175.

Bezerra, A. S.; Silva, C. R. D. de S., Brito, D. A. S., Silva, H. F. da. (2018). Avaliação psicológica no trânsito. Psicologia.pt. Disponível em: https://www.psicologia.pt/artigos/textos/A1159.pdf. Acessado em: 10 Mar. 2021.

Borges, C. D., Rodriguez, S. Y. S. (2020). Psicologia do trânsito: perspectivas atuais do psicólogo brasileiro em atuação no trânsito. Revista Saúde e Desenvolvimento Humano, 8 (1), s/p. Disponível em: https://revistas.unilasalle.edu.br/index.php/saude desenvolvimento/article/view/3094/pdf. Acessado em: 10 Mar. 2021.

Conselho Federal de Psicologia (CFP). (2019a). Avaliação Psicológica Compulsória. Brasília: CFP. Disponível em: https://satepsi.cfp.org.br/docs/1910-DialogosEd10Encarte.pdf. Acessado em 28 Abr. 2021.

Conselho Federal de Psicologia (CFP). (2005). Código de Ética Profissional doPsicólogo. Brasília: CFP. Disponível em: https://site.cfp.org.br/wp-content/uploads/2012/07/codigo-de-eticapsicologia.pdf. Acessado em: 13 Mar. 2021.

Conselho Federal de Psicologia (CFP). Resolução CFP No. 06/2019. (2019b). Institui regras para a elaboração de documentos escritos produzidos pela (o) psicóloga (o) no exercício profissional e revoga a Resolução CFP no 15/1996, a Resolução CFP no 07/2003 e a Resolução CFP noㅡ 04/2019. Brasília: CFP. Disponível em: https://www.in.gov.br/materia/lasset publisher/Kujrw0TZC2Mb/content/id/69440957/do1-2019-04-01-resolucao-n-6-de-29de-marco-de-2019-69440920. Acessado em: 13 Mar. 2021.

Conselho Federal de Psicologia (CFP). Resolução $n^{\circ}$ 007/2009. (2009). Revoga a resolução 012/2000 e institui normas e procedimento para a avaliação psicológica no contexto do trânsito. Brasília: CFP. Disponível em: https://site.cfp.org.br/wpcontent/uploads/2009/08/resolucao2009 07.pdf. Acessado em: 13 Mar. 2021.

Conselho Federal de Psicologia (CFP). Resolução no 09/2018. (2018). Estabelece diretrizes para a realização de Avaliação Psicológica no exercício profissional da psicóloga e do psicólogo, regulamenta o Sistema de Avaliação de Testes Psicológicos - SATEPSI e revoga as Resoluções $n^{\circ}$ 002/2003, no 006/2004 e n 005/2012 e Notas Técnicas n 01/2017 e 02/2017. Brasília: CFP. Disponível em: https://www.in.gov.br/web/dou/-/resolucao-n-9-de-25-de-abril-de2018-

12526419\#: :text=Estabelece\%20diretrizes\%20para\%20a\%20realiza\%C3\%A7\%C3\%A30,\%2 F2017\%20e\%2002\%2F2017. Acessado em: 28 Abr. 2021.

Ferreira, A. B. de O. (2010). Mini Aurélio: o dicionário da língua portuguesa. 8. ed. Curitiba: Editora Positivo. ISBN: 9788538580812.

Lins, M. R. C., Borsa, J. C. (2017). Avaliação Psicológica: aspectos teóricos e práticos. Petrópolis: Vozes. ISBN: 978-85-326-5414-4.

Nakano, T.C., Sampaio, M. H. L., Silva, A. B. (2011). Atenção e inteligência em candidatos a primeira carteira nacional de habilitação. Boletim de Psicologia, 61 (134), 63-78. Disponível em: http://pepsic.bvsalud.org/pdf/bolpsi/v61n134/v61n134a06.pdf. Acessado em: 14 Mar. 2021.

Rev. Psicol Saúde e Debate. Jun., 2021:7(1): 315-326. 
Silva, J. A. da; Mendes, D. F.; Silva, L. de A. M. (2018). Contribuições dos testes para a avaliação psicológica no trânsito. Psicologia e Saúde em Debate, 1, 9-43. Disponível em: http://psicodebate.dpgpsifpm.com.br/index.php/periodico/article/view/179/122. Acessado em: 14 Mar. 2021. 